4

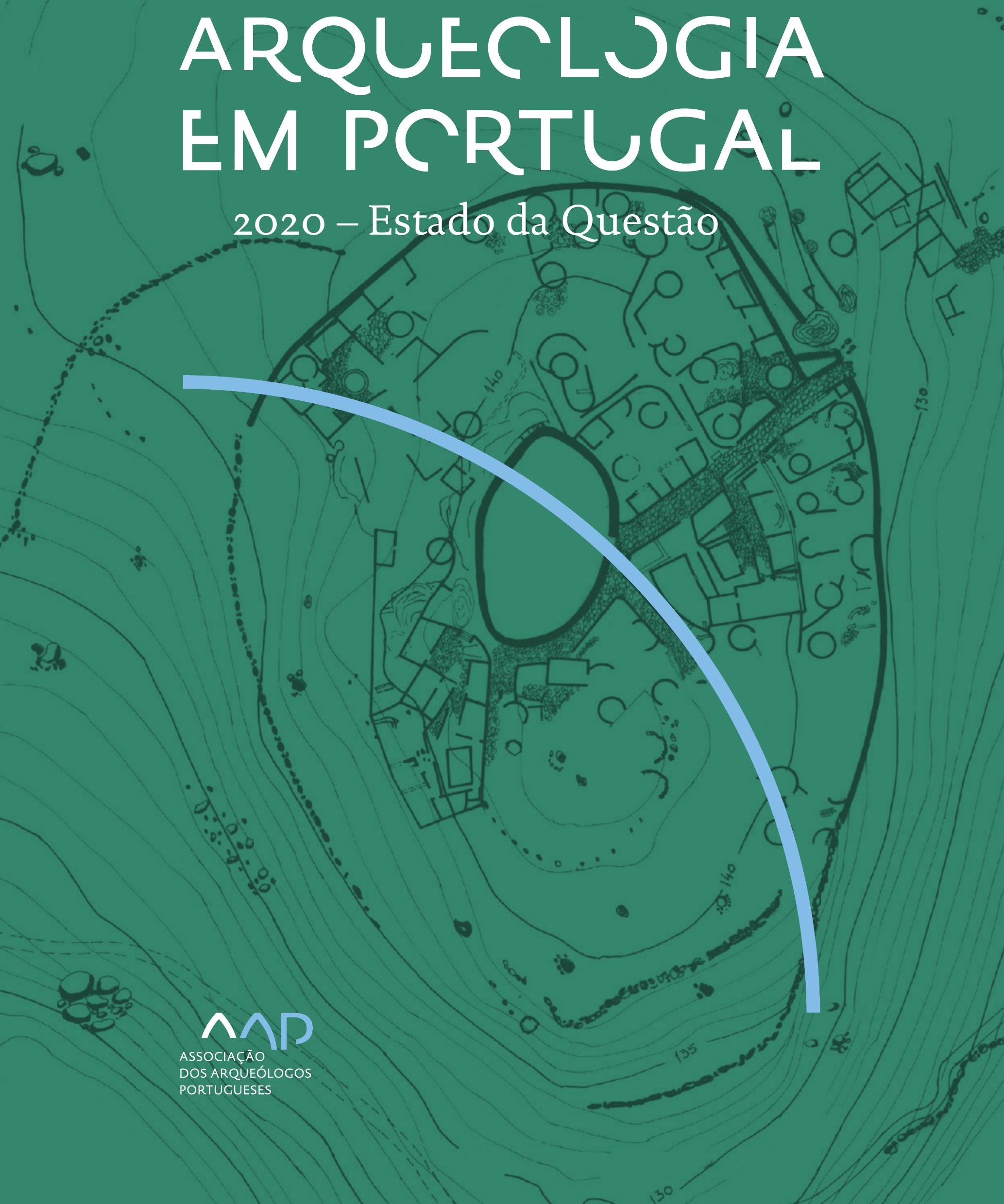


Coordenação editorial: José Morais Arnaud, César Neves e Andrea Martins Design gráfico: Flatland Design

AAP - ISBN: 978-972-9451-89-8

CITCEM - ISBN: 978-989-8970-25-1

Associação dos Arqueólogos Portugueses e CITCEM

Lisboa, 2020

O conteúdo dos artigos é da inteira responsabilidade dos autores. Sendo assim a Associação dos Arqueólogos Portugueses declina qualquer responsabilidade por eventuais equívocos ou questões de ordem ética e legal.

Desenho de capa:

Planta do castro de Monte Mozinho (Museu Municipal de Penafiel).

\section{$\hat{\wedge} \mathrm{P}$}

DOS ARQUEÓLOGOS PORTUGUESES

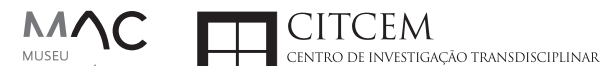
MUSEU
ARQUELLÓGICO
DO CARMO
U.PORTO

FLUP FACULDADE DE LETRAS
UNIVERSIDADE DO PORTO

Apoio

EC para a Ciência 


\section{Índice}

15 Prefácio

José Morais Arnaud

\section{Historiografia e Teoria}

17 Território, comunidade, memória e emoção: a contribuição da história da arqueologia (algumas primeiras e breves reflexões)

Ana Cristina Martins

25 Como descolonizar a arqueologia portuguesa?

Rui Gomes Coelho

41 Arqueologia e Modernidade: uma revisitação pessoal e breve de alguns aspetos da obra homónima de Julian Thomas de 2004

Vítor Oliveira Jorge

57 Dados para a História das Mulheres na Arqueologia portuguesa, dos finais do século XIX aos inícios do século XX: números, nomes e tabelas

Filipa Dimas / Mariana Diniz

73 Retractos da arqueologia portuguesa na imprensa: (in)visibilidades no feminino

Catarina Costeira / Elsa Luís

85 Arqueologia e Arqueólogos no Norte de Portugal Jacinta Bugalhão

101 Vieira Guimarães (1864-1939) e a arqueologia em Tomar: uma abordagem sobre o território e as gentes

João Amendoeira Peixoto / Ana Cristina Martins

115 Os memoráveis? A arqueologia algarvia na imprensa nacional e regional na presente centúria (2001-2019): características, visões do(s) passado(s) e a arqueologia

enquanto marca

Frederico Agosto / João Silva

129 A Evolução da Arqueologia Urbana e a Valorização Patrimonial no Barlavento Algarvio: Os casos de Portimão e Silves

Artur Mateus / Diogo Varandas / Rafael Boavida

\section{Gestão, Valorização e Salvaguarda do Património}

145 O Caderno Reivindicativo e as condições de trabalho em Arqueologia Miguel Rocha / Liliana Matias Carvalho / Regis Barbosa / Mauro Correia / Sara Simões / Jacinta Bugalhão / Sara Brito / Liliana Veríssimo Carvalho / Richard Peace / Pedro Peça / Cézer Santos

155 Os Estudos de Impacte Patrimonial como elemento para uma estratégia sustentável de minimização de impactes no âmbito de reconversões agrícolas Tiago do Pereiro

165 Salvaguarda de Património arqueológico em operações florestais: gestão e sensibilização Filipa Bragança / Gertrudes Zambujo / Sandra Lourenço / Belém Paiva / Carlos Banha / Frederico Tatá Regala / Helena Moura / Jacinta Bugalhão / João Marques / José Correia / Pedro Faria / Samuel Melro

179 Os valores do Património: uma investigação sobre os Sítios Pré-históricos de Arte Rupestre do Vale do Rio Côa e de Siega Verde José Paulo Francisco 
189 Conjugando recursos arqueológicos e naturais para potenciar as visitas ao Geoparque Litoral de Viana do Castelo (Noroeste de Portugal)

Hugo A. Sampaio / Ana M.S. Bettencourt / Susana Marinho / Ricardo Carvalhido

203 Áreas de Potencial Arqueológico na Região do Médio Tejo: Modelo Espacial Preditivo Rita Ferreira Anastácio / Ana Filipa Martins / Luiz Oosterbeek

223 Património Arqueológico e Gestão Territorial: O contributo da Arqueologia para a revisão do PDM de Avis

Ana Cristina Ribeiro

237 A coleção arqueológica do extinto Museu Municipal do Porto - Origens, Percursos e Estudos

Sónia Couto

251 Valpaços - uma nova carta arqueológica

Pedro Pereira / Maria de Fátima Casares Machado

263 Arqueologia na Cidade de Peniche

Adriano Constantino / Luís Rendeiro

273 Arqueologia Urbana: a cidade de Lagos como caso de Estudo Cátia Neto

285 Estratégias de promoção do património cultural subaquático nos Açores. O caso da ilha do Faial

José Luís Neto / José Bettencourt / Luís Borges / Pedro Parreira

297 Carta Arqueológica da Cidade Velha: Uma primeira abordagem

Jaylson Monteiro / Nireide Tavares / Sara da Veiga / Claudino Ramos / Edson Brito /

Carlos Carvalho / Francisco Moreira / Adalberto Tavares

311 Antropologia Virtual: novas metodologias para a análise morfológica e funcional Ricardo Miguel Godinho / Célia Gonçalves

\section{Didáctica da Arqueologia}

327 Como os projetos de Arqueologia podem contribuir para uma comunidade culturalmente mais consciente Alexandra Figueiredo / Claúdio Monteiro / Adolfo Silveira / Ricardo Lopes

337 Educação Patrimonial - Um cidadão esclarecido é um cidadão ativo! Ana Paula Almeida

351 A aproximação da Arqueologia à sala de aula: um caso de estudo no $3^{\circ}$ ciclo do Ensino Básico Luís Serrão Gil

363 Arqueologia 3.o - Pensar e comunicar a Arqueologia para um futuro sustentável Mónica Rolo

377 “Conversa de Arqueólogos" - Divulgar a Arqueologia em tempos de Pandemia Diogo Teixeira Dias

389 Escola Profissional de Arqueologia: desafios e oportunidades Susana Nunes / Dulcineia Pinto / Júlia Silva / Ana Mascarenhas

399 Os Museus de Arqueologia e os Jovens: a oferta educativa para o público adolescente Beatriz Correia Barata / Leonor Medeiros

411 O museu universitário como mediador entre a ciência e a sociedade: o exemplo da secção de arqueologia no Museu de História Natural e da Ciência da Universidade do Porto (MHNC-UP)

Rita Gaspar 
421 Museu de Lanifícios: Real Fábrica de Panos. Atividades no âmbito da Arqueologia Beatriz Correia Barata / Rita Salvado

427 Arqueologia Pública e o caso da localidade da Mata (Torres Novas) Cláudia Manso / Ana Rita Ferreira / Cristiana Ferreira / Vanessa Cardoso Antunes

431 Do sítio arqueológico ao museu: um percurso (também) didático Lídia Fernandes

447 Estão todos convidados para a Festa! E para dançar também... O projecto do Serviço Educativo do Museu Arqueológico do Carmo na $5^{\underline{a}}$ Edição da Festa da Arqueologia Rita Pires dos Santos

459 O “Clã de Carenque”, um projeto didático de arqueologia Eduardo Gonzalez Rocha

469 Mediação cultural: peixe que puxa carroça nas Ruínas Romanas de Troia Inês Vaz Pinto / Ana Patrícia Magalhães / Patrícia Brum / Filipa Santos

481 Didática Arqueológica, experiências do Projeto Mértola Vila Museu Maria de Fátima Palma / Clara Rodrigues / Susana Gómez / Lígia Rafael

\section{Arte Rupestre}

497 Os inventários de arte rupestre em Portugal Mila Simões de Abreu

513 O projeto FIRST-ART - conservação, documentação e gestão das primeiras manifestações de arte rupestre no Sudoeste da Península Ibérica: as grutas do Escoural e Maltravieso Sara Garcês / Hipólito Collado / José Julio García Arranz / Luiz Oosterbeek / António Carlos Silva / Pierluigi Rosina / Hugo Gomes / Anabela Borralheiro Pereira / George Nash / Esmeralda Gomes / Nelson Almeida / Carlos Carpetudo

523 Trabalhos de documentação de arte paleolítica realizados no âmbito do projeto PalæoCôa André Tomás Santos / António Fernando Barbosa / Luís Luís / Marcelo Silvestre / Thierry Aubry

537 Imagens fantasmagóricas, silhuetas elusivas: as figuras humanas na arte do Paleolítico Superior da região do Côa Mário Reis

$55^{1}$ Os motivos zoomórficos representados nas placas de tear de Vila Nova de São Pedro (Azambuja, Portugal) Andrea Martins / César Neves / José M. Arnaud / Mariana Diniz

571 Arte Rupestre do Monte de Góios (Lanhelas, Caminha). Síntese dos resultados dos trabalhos efectuados em 2007-2009 Mário Varela Gomes

599 Gravuras rupestres de barquiformes no Monte de S. Romão, Guimarães, Noroeste de Portugal Daniela Cardoso

613 Círculos segmentados gravados na Bacia do Rio Lima (Noroeste de Portugal): contributos para o seu estudo Diogo Marinho / Ana M.S. Bettencourt / Hugo Aluai Sampaio

631 Equídeos gravados no curso inferior do Rio Mouro, Monção (NW Portugal). Análise preliminar Coutinho, L.M. / Bettencourt, A.M.S / Sampaio, Hugo A.S

645 Paletas na Arte Rupestre do Noroeste de Portugal. Inventário preliminar Bruna Sousa Afonso / Ana M. S. Bettencourt / Hugo A. Sampaio 


\section{Pré-História}

661 O projeto Miño/Minho: balanço de quatro anos de trabalhos arqueológicos Sérgio Monteiro-Rodrigues / João Pedro Cunha-Ribeiro / Eduardo Méndez-Quintas / Carlos Ferreira / Pedro Xavier / José Meireles / Alberto Gomes / Manuel Santonja / Alfredo Pérez-González

677 A ocupação paleolítica da margem esquerda do Baixo Minho: a indústria lítica do sítio de Pedreiras 2 (Monção, Portugal) e a sua integração no contexto regional Carlos Ferreira / João Pedro Cunha-Ribeiro / Sérgio Monteiro-Rodrigues / Eduardo Méndez-Quintas / Pedro Xavier / José Meireles / Alberto Gomes / Manuel Santonja / Alfredo Pérez-González

693 O sítio acheulense do Plistocénico médio da Gruta da Aroeira Joan Daura / Montserrat Sanz / Filipa Rodrigues / Pedro Souto / João Zilhão

703 As sociedades neandertais no Barlavento algarvio: modelos preditivos com recurso aos SIG

Daniela Maio

715 A utilização de quartzo durante o Paleolítico Superior no território dos vales dos rios Vouga e Côa

Cristina Gameiro / Thierry Aubry / Bárbara Costa / Sérgio Gomes / Luís Luís / Carmen Manzano / André Tomás Santos

733 Uma perspetiva diacrónica da ocupação do concheiro do Cabeço da Amoreira (Muge, Portugal) a partir da tecnologia lítica Joana Belmiro / João Cascalheira / Célia Gonçalves

745 Novos dados sobre a Pré-história Antiga no concelho de Palmela. A intervenção arqueológica no sítio do Poceirão I

Michelle Teixeira Santos

757 Problemas em torno de Datas Absolutas Pré-Históricas no Norte do Alentejo Jorge de Oliveira

771 Povoamento pré-histórico nas áreas montanhosas do NO de Portugal: o Abrigo 1 de Vale de Cerdeira Pedro Xavier / José Meireles / Carlos Alves

783 Apreciação do povoamento do Neolítico Inicial na Baixa Bacia do Douro. A Lavra I (Serra da Aboboreira) como caso de estudo Maria de Jesus Sanches

797 O Processo de Neolitização na Plataforma do Mondego: os dados do Sector C do Outeiro dos Castelos de Beijós (Carregal do Sal)

João Carlos de Senna-Martinez / José Manuel Quintã Ventura / Andreia Carvalho / Cíntia Maurício

823 Novos trabalhos na Lapa da Bugalheira (Almonda, Torres Novas) Filipa Rodrigues / Pedro Souto / Artur Ferreira / Alexandre Varanda / Luís Gomes / Helena Gomes / João Zilhão

837 A pedra polida e afeiçoada do sítio do Neolítico médio da Moita do Ourives (Benavente, Portugal)

César Neves

857 Casal do Outeiro (Encarnação, Mafra): novos contributos para o conhecimento do povoamento do Neolítico final na Península de Lisboa.

Cátia Delicado / Carlos Maneira e Costa / Marta Miranda / Ana Catarina Sousa

873 Stresse infantil, morbilidade e mortalidade no sítio arqueológico do Neolítico Final/ Calcolítico ( $4^{\circ}$ e $3^{\circ}$ milénio a.C.) do Monte do Carrascal 2 (Ferreira do Alentejo, Beja) Liliana Matias de Carvalho / Sofia N. Wasterlain 
885 Come together: O Conjunto Megalítico das Motas (Monção, Viana do Castelo) e as expressões Campaniformes do Alto Minho Ana Catarina Basílio / Rui Ramos

899 Trabalhos arqueológicos no sítio Calcolítico da Pedreira do Poio Carla Magalhães / João Muralha / Mário Reis / António Batarda Fernandes

913 O sítio arqueológico de Castanheiro do Vento. Da arquitectura do sítio à arquitectura de um território João Muralha Cardoso

925 Estudo zooarqueológico das faunas do Calcolítico final de Vila Nova de São Pedro (Azambuja, Portugal): Campanhas de 2017 e 2018 Cleia Detry / Ana Catarina Francisco / Mariana Diniz / Andrea Martins / César Neves / José Morais Arnaud

943 As faunas depositadas no Museu Arqueológico do Carmo provenientes de Vila Nova de São Pedro (Azambuja): as campanhas de 1937 a 1967 Ana Catarina Francisco / Cleia Detry / César Neves / Andrea Martins / Mariana Diniz / José Morais Arnaud

959 Análise funcional de material lítico em sílex do castro de Vila Nova de S. Pedro (Azambuja, Portugal): uma primeira abordagem Rafael Lima

971 O recinto da Folha do Ouro 1 (Serpa) no contexto dos recintos de fossos calcolíticos alentejanos

António Carlos Valera / Tiago do Pereiro / Pedro Valério / António M. Monge Soares

\section{Proto-História}

987 Produção de sal marinho na Idade do Bronze do noroeste Português. Alguns dados para uma reflexão

Ana M. S. Bettencourt / Sara Luz / Nuno Oliveira / Pedro P. Simões / Maria Isabel C. Alves / Emílio Abad-Vidal

1001 A estátua-menir do Pedrão ou de São Bartolomeu do Mar (Esposende, noroeste de Portugal) no contexto arqueológico da fachada costeira de entre os rios Neiva e Cávado Ana M. S. Bettencourt / Manuel Santos-Estévez / Pedro Pimenta Simões / Luís Gonçalves

1015 O Castro do Muro (Vandoma/Baltar, Paredes) - notas para uma biografia de ocupação da Idade do Bronze à Idade Média

Maria Antónia D. Silva / Ana M. S. Bettencourt / António Manuel S. P. Silva / Natália Félix

1031 Do Bronze Final à Idade Média - continuidades e hiatos na ocupação de Povoados em Oliveira de Azeméis João Tiago Tavares / Adriaan de Man

1041 As faunas do final da Idade do Bronze no Sul de Portugal: leituras desde o Outeiro do Circo (Beja)

Nelson J. Almeida / Íris Dias / Cleia Detry / Eduardo Porfírio / Miguel Serra

1055 A Espada do Monte das Oliveiras (Serpa) - uma arma do Bronze Pleno do Sudoeste Rui M. G. Monge Soares / Pedro Valério / Mariana Nabais / António M. Monge Soares

1065 São Julião da Branca (Albergaria-a-Velha) - Investigação e valorização de um povoado do Bronze Final

António Manuel S. P. Silva / Paulo A. P. Lemos / Sara Almeida e Silva / Edite Martins de Sá

1083 Do castro de S. João ao Mosteiro de Santa Clara: notícia de uma intervenção arqueológica, em Vila do Conde Rui Pinheiro 
1095 O castro de Ovil (Espinho), um quarto de século de investigação - resultados e questões em aberto

Jorge Fernando Salvador / António Manuel S. P. Silva

1111 O Castro de Salreu (Estarreja), um povoado proto-histórico no litoral do Entre Douro e Vouga

Sara Almeida e Silva / António Manuel S. P. Silva / Paulo A. P. Lemos / Edite Martins de Sá

1127 Castro de Nossa Senhora das Necessidades (Sernancelhe): uma primeira análise artefactual Telma Susana O. Ribeiro

${ }_{1141}$ A cividade de Bagunte. O estado atual da investigação Pedro Brochado de Almeida

1153 Zoomorfos na cerâmica da Idade do Ferro no NW Peninsular: inventário, cronologias e significado Nuno Oliveira / Cristina Seoane

1163 Vasos gregos em Portugal: diferentes maneiras de contar a história do intercâmbio cultural na Idade do Ferro

Daniela Ferreira

1175 Os exotica da necrópole da Idade do Ferro do Olival do Senhor dos Mártires (Alcácer do Sal) no seu contexto regional

Francisco B. Gomes

\section{Antiguidade Clássica e Tardia}

1191 O uso de madeira como combustível no sítio da Quinta de Crestelos (Baixo Sabor): da Idade do Ferro à Romanização Filipe Vaz / João Tereso / Sérgio Simões Pereira / José Sastre / Javier Larrazabal Galarza / Susana Cosme / José António Pereira / Israel Espi

1207 Cultivos de Época Romana no Baixo Sabor: continuidade em tempos de mudança? João Pedro Tereso / Sérgio Simões Pereira / Filipe Santos / Luís Seabra / Filipe Vaz

1221 A casa romana na Hispânia: aplicação dos modelos itálicos nas províncias ibéricas Fernanda Magalhães / Diego Machado / Manuela Martins

1235 As pinturas murais romanas da Rua General Sousa Machado, n. ${ }^{5}$ 1, Chaves José Carvalho

1243 Trás do Castelo (Vale de Mir, Pegarinhos, Alijó) - Uma exploração agrícola romana do Douro

Tony Silvino / Pedro Pereira

1255 A sequência de ocupação no quadrante sudeste de Bracara Augusta: as transformações de uma unidade doméstica Lara Fernandes / Manuela Martins

1263 Os Mosaicos com decoração geométrica e geométrico-vegetalista dos sítios arqueológicos da área do Conuentus Bracaraugustanus. Novas abordagens quanto à conservação, restauro, decoração e datação Maria de Fátima Abraços / Licínia Wrench

1277 “Casa Romana” do Castro de São Domingos (Cristelos, Lousada): Escavação, Estudo e Musealização Paulo André de P. Lemos

1291 A arqueobotânica no Castro de Guifões (Matosinhos, Noroeste de Portugal): O primeiro estudo carpológico

Luís Seabra / Andreia Arezes / Catarina Magalhães / José Varela / João Pedro Tereso 
1305 Um Horreum Augustano na Foz do Douro (Monte do Castelo de Gaia, Vila Nova de Gaia) Rui Ramos

1311 Ponderais romanos na Lusitânia: padrões, formas, materiais e contextos de utilização Diego Barrios Rodríguez

1323 Um almofariz centro-itálico na foz do Mondego

Marco Penajoia

1335 Estruturas romanas de Carnide - Lisboa Luísa Batalha / Mário Monteiro / Guilherme Cardoso

1347 O contexto funerário do sector da "necrópole NO" da Rua das Portas de S. Antão (Lisboa): o espaço, os artefactos, os indivíduos e a sua interconectividade na interpretação do passado Sílvia Loja, José Carlos Quaresma, Nelson Cabaço, Marina Lourenço, Sílvia Casimiro, Rodrigo Banha da Silva, Francisca Alves-Cardoso

${ }_{1361}$ Povoamento em época Romana na Amadora - resultados de um projeto pluridisciplinar Gisela Encarnação / Vanessa Dias

1371 A Arquitectura Residencial em Mirobriga (Santiago do Cacém): contributo a partir de um estudo de caso Filipe Sousa / Catarina Felício

${ }_{1385}$ O fim do ciclo. Saneamento e gestão de resíduos nos edifícios termais de Mirobriga (Santiago do Cacém)

Catarina Felício / Filipe Sousa

1399 Balsa, Topografia e Urbanismo de uma Cidade Portuária Vítor Silva Dias / João Pedro Bernardes / Celso Candeias / Cristina Tété Garcia

1413 No Largo das Mouras Velhas em Faro (2017): novas evidências da necrópole norte de Ossonoba e da sua ocupação medieval Ricardo Costeira da Silva / Paulo Botelho / Fernando Santos / Liliana Nunes

1429 Instrumentos de pesca recuperados numa fábrica de salga em Ossonoba (Faro) Inês Rasteiro / Ricardo Costeira da Silva / Paulo Botelho

1439 A Necrópole Romana do Eirô, Duas Igrejas (Penafiel): intervenção arqueológica de 2016 Laura Sousa / Teresa Soeiro

1457 Ritual, descarte ou afetividade? A presença de Canis lupus familiaris na Necrópole Noroeste de Olisipo (Lisboa)

Beatriz Calapez Santos / Sofia Simões Pereira / Rodrigo Banha da Silva / Sílvia Casimiro / Cleia Detry / Francisca Alves Cardoso

1467 Dinâmicas económicas em Bracara na Antiguidade Tardia Diego Machado / Manuela Martins / Fernanda Magalhães / Natália Botica

1479 Cerâmicas e Vidros da Antiguidade Tardia do Edifício sob a Igreja do Bom Jesus (Vila Nova de Gaia) Joaquim Filipe Ramos

1493 Novos contributos para a topografia histórica de Mértola no período romano e na Antiguidade Tardia Virgílio Lopes

\section{8. Época Medieval}

1511 Cerâmicas islâmicas no Garb setentrional "português": algumas evidências e incógnitas Constança dos Santos / Helena Catarino / Susana Gómez / Maria José Gonçalves / Isabel Inácio / Gonçalo Lopes / Jacinta Bugalhão / Sandra Cavaco / Jaquelina Covaneiro / Isabel Cristina Fernandes / Ana Sofia Gomes 
1525 Contributo para o conhecimento da cosmética islâmica, em Silves, durante a Idade Média Rosa Varela Gomes

1537 Yábura e o seu território - uma análise histórico-arqueológica de Évora entre os séculos VIII-XII José Rui Santos

1547 A encosta sul do Castelo de Palmela - resultados preliminares da escavação arqueológica Luís Filipe Pereira / Michelle Teixeira Santos

1559 A igreja de São Lourenço (Mouraria, Lisboa): um conjunto de silos e de cerâmica medieval islâmica

Andreia Filipa Moreira Rodrigues

1571 O registo material de movimentações populacionais no Médio Tejo, durante os séculos XII-XIII. Dois casos de "sunken featured buildings", nos concelhos de Cartaxo e Torres Novas Marco Liberato / Helena Santos / Nuno Santos

1585 O nordeste transmontano nos alvores da Idade média. Notas para reflexão Ana Maria da Costa Oliveira

1601 Sepulturas escavadas na rocha do Norte de Portugal e do Vale do Douro: primeiros resultados do Projecto SER-NPVD

Mário Jorge Barroca / César Guedes / Andreia Arezes / Ana Maria Oliveira

1619 "Portucalem Castrum Novum" entre o Mediterrâneo e o Atlântico: o estudo dos materiais cerâmicos alto-medievais do arqueossítio da rua de D. Hugo, nํ. 5 (Porto) João Luís Veloso

1627 A Alta Idade Média na fronteira de Lafões: notas preliminares sobre a Arqueologia no Concelho de Vouzela

Manuel Luís Real / Catarina Tente

1641 Um conjunto cerâmico medieval fora de portas: um breve testemunho aveirense Susana Temudo

${ }_{1651}$ Os Lóios do Porto: uma perspetiva integrada no panorama funerário da Baixa Idade Média à Época Moderna em meios urbanos em Portugal

Ana Lema Seabra

1659 O Caminho Português Interior de Santiago como eixo viário na Idade Média Pedro Azevedo

1665 Morfologia Urbana: Um exercício em torno do Castelo de Ourém André Donas-Botto / Jaqueline Pereira

1677 Intervenção arqueológica na Rua Marquês de Pombal/Largo do Espírito Santo (Bucelas, Loures)

Florbela Estêvão / Nathalie Antunes-Ferreira / Dário Ramos Neves / Inês Lisboa

1691 O Cemitério Medieval do Poço do Borratém e a espacialidade funerária na cidade de Lisboa Inês Belém / Vanessa Filipe / Vasco Noronha Vieira / Sónia Ferro / Rodrigo Banha da Silva

1705 Um Espaço Funerário Conventual do séc. XV em Lisboa: o caso do Convento de São Domingos da Cidade Sérgio Pedroso / Sílvia Casimiro / Rodrigo Banha da Silva / Francisca Alves Cardoso

\section{9. Época Moderna e Contemporânea}

1721 Arqueologia Moderna em Portugal: algumas reflexões críticas em torno da quantificação de conjuntos cerâmicos e suas inferências históricas e antropológicas Rodrigo Banha da Silva / André Bargão / Sara da Cruz Ferreira

1733 Faianças de dois contextos entre os finais do século XVI e XVIII do Palácio dos Condes de Penafiel, Lisboa

Martim Lopes / Tomás Mesquita 
1747 Um perfil de consumo do século XVIII na foz do Tejo: O caso do Mercado da Ribeira, Lisboa Sara da Cruz Ferreira / Rodrigo Banha da Silva / André Bargão

1761 Os Cachimbos dos Séculos XVII e XVIII do Palácio Mesquitela e Convento dos Inglesinhos (Lisboa)

Inês Simão / Marina Pinto / João Pimenta / Sara da Cruz Ferreira / André Bargão / Rodrigo Banha da Silva

1775 "Tomar os fumos da erua que chamão em Portugal erua sancta». Estudo de Cachimbos provenientes da Rua do Terreiro do Trigo, Lisboa

Miguel Martins de Sousa / José Pedro Henriques / Vanessa Galiza Filipe

1787 Cachimbos de Barro Caulínitico da Sé da Cidade Velha (República de Cabo Verde)

Rodrigo Banha da Silva / João Pimenta / Clementino Amaro

1801 Algumas considerações sobre espólio não cerâmico recuperado no Largo de Jesus (Lisboa) Carlos Boavida

1815 Adereços de vidro, dos séculos XVI-XVIII, procedentes do antigo Convento de Santana de Lisboa (anéis, braceletes e contas)

Joana Gonçalves / Rosa Varela Gomes / Mário Varela Gomes

1837 Da ostentação, luxo e poder à simplicidade do uso quotidiano: arqueologia e simbologia de joias e adornos da Idade Moderna Portuguesa Jéssica Iglésias

1849 Os amuletos em Portugal - dos objetos às superstições: o coral vermelho Alexandra Vieira

1865 Cerâmicas de Vila Franca de Xira nos séculos XV e XVI Eva Pires

1879 «Não passa por teu o que me pertence». Marcas de individualização associadas a faianças do Convento de Nossa Senhora de Aracoeli, Alcácer do Sal Catarina Parreira / Íris Fragoso / Miguel Martins de Sousa

1891 Cerâmica de Leiria: alguns focos de produção

Jaqueline Pereira / André Donas-Botto

1901 Os Fornos na Rua da Biquinha, em Óbidos Hugo Silva / Filipe Oliveira

1909 A casa de Pêro Fernandes, contador dos contos de D. Manuel I: o sítio arqueológico da Silha do Alferes, Seixal (século XVI) Mariana Nunes Ferreira

1921 O Alto da Vigia (Sintra) e a vigilância e defesa da costa Alexandre Gonçalves / Sandra Santos

1937 O contexto da torre sineira da Igreja de Santa Maria de Loures Paulo Calaveira / Martim Lopes

1949 A Necrópole do Hospital Militar do Castelo de São Jorge e as práticas funerárias na Lisboa de Época Moderna Susana Henriques / Liliana Matias de Carvalho / Ana Amarante / Sofia N. Wasterlain

1963 SAND - Sarilhos Grandes Entre dois Mundos: o adro da Igreja e a Paleobiologia dos ossos humanos recuperados

Paula Alves Pereira / Roger Lee Jesus / Bruno M. Magalhães

1975 Expansão urbana da vila de Cascais no século XVII e XVIII: a intervenção arqueológica na Rua da Vitória no 15 a 17

Tiago Pereira / Vanessa Filipe

1987 Novos dados para o conhecimento do Urbanismo de Faro em época Moderna Ana Rosa 
1995 Um exemplo de Arqueologia Urbana em Alcoutim: o Antigo Edifício dos CTT Marco Fernandes / Marta Dias / Alexandra Gradim / Virgílio Lopes / Susana Gómez Martínez

2007 Palácio dos Ferrazes (Rua das Flores/Rua da Vitória, Porto): a cocheira de Domingos Oliveira Maia

Francisco Raimundo

2021 As muitas vidas de um edifício urbano: História, Arqueologia e Antropologia no antigo Recreatório Paroquial de Penafiel Helena Bernardo / Jorge Sampaio / Marta Borges

2035 O convento de Nossa Senhora da Esperança de Ponta Delgada: o contributo da arqueologia para o conhecimento de um monumento identitário João Gonçalves Araújo / N’Zinga Oliveira

2047 Arqueologia na ilha do Corvo... em busca da capela de Nossa Senhora do Rosário Tânia Manuel Casimiro / José Luís Neto / Luís Borges / Pedro Parreira

2059 Perdidos à vista da Costa. Trabalhos arqueológicos subaquáticos na Barra do Tejo Jorge Freire / José Bettencourt / Augusto Salgado

2071 Arqueologia marítima em Cabo Verde: enquadramento e primeiros resultados do projecto CONCHA

José Bettencourt / Adilson Dias / Carlos Lima / Christelle Chouzenoux / Cristóvão Fonseca / Dúnia Pereira / Gonçalo Lopes / Inês Coelho / Jaylson Monteiro / José Lima / Maria Eugénia Alves / Patrícia Carvalho / Tiago Silva

2085 Trabalhos arqueológicos na Cidade Velha (Ribeira Grande de Santiago, Cabo Verde): reflexões sobre um projecto de investigação e divulgação patrimonial André Teixeira / Jaylson Monteiro / Mariana Mateus / Nireide Tavares / Cristovão Fonseca / Gonçalo C. Lopes / Joana Bento Torres / Dúnia Pereira / André Bargão / Aurélie Mayer / Bruno Zélie / Carlos Lima / Christelle Chouzenoux / Inês Henriques / Inês Pinto Coelho / José Lima / Patrícia Carvalho / Tiago Silva

2103 A antiga fortificação de Quelba / Khor Kalba (E.A.U.). Resultados de quatro campanhas de escavações, problemáticas e perspectivas futuras Rui Carita / Rosa Varela Gomes / Mário Varela Gomes / Kamyar Kamyad

2123 Colónias para homens novos: arqueologia da colonização agrária fascista no noroeste ibérico Xurxo Ayán Vila / José Mạ . Señorán Martín 


\title{
UM HORREUM AUGUSTANO NA FOZ DO DOURO (MONTE DO CASTELO DE GAIA, VILA NOVA DE GAIA)
}

Rui Ramos ${ }^{1}$

\begin{abstract}
RESUMO
A escavação arqueológica realizada entre Fevereiro de 2016 e Novembro de 2018 pela Era Arqueologia S.A. na vertente Nordeste do Monte do Castelo de Gaia, pôs em evidência uma lata sequência ocupacional cuja génese remonta ao século IV a.C. e que se prolongou - entre hiatos mais ou menos prolongados - até ao século XX. Das ocupações mais relevantes dentro desta ampla diacronia (idade do ferro, romana e medieval), optamos ora por nos debruçar sobre a que nos parece mais significativa, porquanto inédita neste âmbito geográfico: um grande edifício de planta rectangular com aproximadamente 300 metros quadrados, datado de entre 30 a 15 a.C. que interpretamos como um Horreum, que poderá ter sido construído no âmbito das campanhas relacionadas com a pacificação da Hispânia Setentrional empreendidas por Augusto.

Palavras-chave: Douro, Castelo de Gaia, Horreum, Romano, Augusto.
\end{abstract}

\begin{abstract}
The archaeological excavation carried out between February 2016 and November 2018 by Era Arqueologia S.A. in the Northeast side of Monte do Castelo de Gaia, highlighted a wide occupational sequence whose genesis dates back to the $4^{\text {th }}$ century $\mathrm{BC}$. and that it extended until the $2 \mathrm{O}^{\text {th }}$ century. Of the most relevant occupations within this wide diachrony (iron age, roman and medieval), we have now chosen to focus on the one that seems most significant to us, since it is unprecedented in this geographical scope: a large rectangular building with approximately 300 square meters, dated from 30 to 15 BC that we interpret as a Horreum, which may have been built in the context of the campaigns related to the pacification of Northern Hispania undertaken by Augustus.
\end{abstract}

Keywords: Douro, Castelo de Gaia hill, Horreum, Roman, Augustus.

\section{CONTEXTUALIZAÇÃO}

O Monte do Castelo de Gaia localiza-se na margem esquerda do Douro, a cerca de 4 quilómetros da sua foz e constitui um marco proeminente na paisagem ribeirinha do curso final do rio. (Figura 1 e Figura 2). Esta colina domina a montante um fundeadouro natural, junto ao qual foram construídos a maior parte dos - hoje célebres - armazéns de Vila Nova de Gaia e constituiria um importante ponto de passagem entre as duas margens até à construção das primeiras travessias fixas desta parte do rio.

Desde a hipotética localização neste local do Portus ou da Cale do Itinerário de Antonino até à existência da fortificação medieva que perdurou na memória e na toponímia da cidade, o Monte do Castelo tem cativado o interesse de cronistas e historiadores ao longos dos séculos e ainda que a arqueologia tenha tardado a entrar em cena, as diversas intervenções realizadas em vários pontos deste monte desde os anos 80 do século XX, (Silva,2020) ainda que não tenham conseguido resgatar ao oblívio o nome antigo do lugar, vieram confirmar um sítio arqueológico de excepcional valor e um importante manancial de informação para o estudo das rotas comerciais costeiras que ligavam o Sul e o Norte da Península desde a antiguidade.

A escavação arqueológica, realizada no âmbito do

1. Era Arqueologia, S.A.; ruiramos@omniknos.pt 
plano de minimizações prévias a um projecto de construção, localiza-se na vertente Nordeste do monte, fronteira a Miragaia na margem oposta e a escassos metros do rio. A área intervencionada ocupa um socalco de planta rectangular à cota de 21 metros no logradouro de um antigo armazém, onde entre 1998 e 2006 funcionou o Hard Club.

Os níveis ocupacionais postos em evidência, intercalados por depósitos coluvionares mais ou menos espessos, abrangem uma longa diacronia balizada entre os séculos IV a.C. e o século XX, (Ramos; Carvalho, 2020) com particular destaque para um habitat da II idade do ferro composto por casas e cabanas de planta circular e um grande edifício de planta rectangular, do tipo horreum, construído em finais do século I a.c. e que sendo o mote da nossa comunicação, passaremos a descrever nos parágrafos seguintes.

As condicionantes impostas pela necessidade de garantir a estabilidade do socalco, cujo muro de contenção ruiu parcialmente em Abril de 2016 e obrigou à interrupção dos trabalhos durante alguns meses, levou a que parte do edifício não fosse intervencionado nesta fase dos trabalhos, nomeadamente a área localizada a Este, junto a um segmento do muro de contenção que apresenta problemas de estabilidade e a área Sul, na confluência com um caminho público.

Uma vez que que a planta do edifício extravasa os limites da área intervencionada, as medidas aqui apresentadas são uma tentativa de padronização das medidas observáveis nos muros postos em evidência no decurso da escavação, com vista a uma aproximação à reconstituição da sua planta original. Assim, foi intervencionada uma área de aproximadamente 140 metros quadrados correspondentes ao espaço interior e muro perimetral do edifício embora as evidências apontem para que o edifício terá pelo menos o dobro desta área.

\section{DESCRIÇÃO DO EDIFÍCIO}

A génese da ocupação romana deste espaço corresponde a um grande edifício de planta rectangular, construído e utilizado entre os anos 30 e 15 a.C. ainda que nos depósitos coluvionares sobre os quais foi fundado tenhamos registado a presença de ânforas itálicas produzidas a partir da segunda metade do século II a.C. , o que denuncia a gradual aproximação desta finisterra à órbita romana. (Figura 3)

O edifício é composto por um único volume, com o embasamento construído em alvenaria de pedra, sem evidências que possam indiciar mais de uma fase construtiva ou remodelações posteriores à sua génese. Durante o período em que o edifício se encontrava funcional ou pouco depois do seu abandono, a fachada Este - virada ao rio - foi obliterada por uma derrocada, pelo que não identificamos qualquer indício da mesma.

O eixo maior do edifício, com orientação Norte-Sul, apresenta um comprimento de pelo menos 33,20 metros. Apesar de não termos identificado indícios da fachada Este, pressupomos que teria a mesma espessura da fachada Oeste - cerca de 80 centímetros - e tendo em consideração que um dos muros internos perpendiculares ao eixo maior apresenta 7,60 metros de comprimento, o edifício teria pelo menos 9,20 metros de largura. Assim, a 33,20 metros de comprimento e 9,20 metros de largura, corresponde uma área de implantação de 305,44 metros quadrados. (Figura 4)

$O$ edifício encontrava-se dividido em 6 cellae às quais atribuímos a designação de Ambiente 1, Ambiente 2, Ambiente 3, Ambiente 4, Ambiente $5 \mathrm{e}$ ambiente 6 . Em todas as cellae existiam 3 muretes longitudinais, 2 adossados aos muros divisórios internos e um murete axial, que teriam como função suportar um tabuado. Estas 6 cellae, de planta rectangular, apresentavam 4,90 metros de largura. A ruína da fachada Este não nos permite aferir o comprimento original dos mesmos, mas o maior segmento conservado de um dos muretes internos, identificado no Ambiente 2, tinha 7,6o metros de comprimento, o que nos permite extrapolar que todos os compartimentos teriam no mínimo esta dimensão. Considerando estas medidas, cada compartimento teria pelo menos uma área de 37,24 metros quadrados, o que corresponde a uma área útil total de 223,44 metros quadrados. (Figura 5)

Em relação à altura do edifício, não nos foi possível identificar qualquer elemento que nos fornecesse informação, já que os muros conservados não excediam os 170 centímetros de altura, sendo que destes, 70 a 80 centímetros correspondem ao alicerce.

Os alicerces distinguem-se do aparelho dos muros pela inclusão de blocos de granito irregulares de maiores dimensões, sendo que em alguns dos alicerces foi colocada uma camada de argila sobre a última fiada de pedra, com o intuito de a regularizar para assentar a primeira fiada de pedra do aparelho do muro. Os muretes longitudinais, talvez por não 
se constituírem como elementos estruturais, não tinham alicerce.

O muro perimetral que constitui a fachada Oeste e a Norte é construído em alvenaria de granito, de dupla face, com 80 centímetros de espessura. O aparelho é composto por blocos poligonais de granito de pequena e média dimensão que formam duas faces regulares e bem aparelhadas e o miolo é composto por blocos toscos de pequena dimensão ligados com argila.

Os 5 muros internos, paralelos ao eixo menor do edifício, delimitavam os 6 compartimentos identificados e eram compostos por alvenaria de granito de dupla face, com 50 centímetros de espessura. Os paramentos destes muros são constituídos por blocos poligonais de pequena e média dimensão bem aparelhados, ligados com argila e argamassa de saibro. O miolo é composto por blocos toscos de granito de pequena e média dimensão e argila. Apenas os muros divisórios entre o Ambiente 3 e o Ambiente $4 \mathrm{e}$ o Ambiente 4 e o Ambiente 5 estão imbricados na fachada Oeste, estando os restantes muros encostados à fachada sem qualquer travamento.

No aparelho de um dos muros internos melhor conservados, entre o Ambiente 2 e o Ambiente 3 identificamos uma fiada horizontal de lajes de granito de pequena e dimensão que parecem indiciar uma transição de aparelho ou de técnica construtiva, mas não identificamos quaisquer indícios preservados do tipo de construção que se desenvolveria acima desta cota.

Os muretes longitudinais identificados apresentam dupla face, com 30 centímetros de espessura e são constituídos por blocos poligonais de granito de pequena dimensão assentes a seco. Estes muretes apresentam entre 30 e 40 centímetros de altura nos Ambientes 6, 1, 2 e 3 e cerca de 60 e 70 centímetros de altura nos Ambientes 4 e 5 .

Não identificamos cerâmica de construção, reutilizada ou não, nos paramentos e no miolo dos muros e dos muretes, sendo que o único material que parece ter sido reutilizada foram fragmentos de mós rotatórias inclusas em alguns dos muros divisórios e muretes e um bloco de uma rocha sedimentar exógena a esta região.

\section{DESCRIÇÃO DA ESTRATIGRAFIA}

Ao contrário de tantos outros sítios de cronologia afins, não identificamos níveis pétreo relacionados com a ruída das paredes ou níveis de telha relacionados com a ruína do tecto, no interior ou no exterior do edifício, A sequência estratigráfica identificada no interior é composta por um depósito areno-argiloso de coloração alaranjada, com 50 a 70 centímetros de espessura provavelmente relacionado com a ruína das paredes, que cobre um depósito arenoso de coloração cinzenta com inclusão de carvões, com 10 a 20 centímetros de espessura e que parece corresponder a um nível de abandono do edifício.

No Ambiente 3 e no Ambiente 4, sob o nível de abandono, identificamos um depósito muito compacto de composição argilosa e coloração laranja com cerca de 5 a 10 centímetros de espessura que se desenvolve em praticamente toda a superfície do compartimento que parece corresponder a um nível coetâneo com a construção ou utilização do edifício, porquanto os muretes longitudinais terem sido construídos por cima dele.

No exterior do edifício, os únicos indícios coevos com a sua construção e utilização são um nível de circulação em saibro, contíguo à fachada Oeste do edifício, um depósito pétreo bastante concentrado que parece resultar do descarte intencional de pedra relacionado com a construção do edifício e uma pequena lareira constituída por fragmentos de ânforas.

\section{INTERPRETAÇÃO}

Os 3 muretes longitudinais identificados em cada uma das 6 cellae escavadas parecem corresponder a apoios para um tabuado que constituiria o nível de circulação do edifício, com paralelos documentados em horrea construídos na Hispânia durante o período Republicano (Domínguez, 2009). Este tipo de estrutura enquadra-se na descrição de Varrão e Columela dos Tabulatum/a, isto é, pavimentos sobre-elevados construídos em madeira que se destinavam a armazenar grão e mantê-lo isolado da humidade e dos roedores. (Domínguez, 2003-2004). O material arqueológico associado aos depósitos coetâneos com a construção e uso do horreum é muito residual, sendo composto maioritariamente por cerâmica de tradição indígena e material anfórico, este de suma importância para o enquadramento temporal do edifício. No interior do Ambiente 4 identificamos vários fragmentos de ânforas da Bética Costeira, 2 fundos de ovóides lusitanas, 2 fragmentos de ânforas Itálicas produzidas no Lácio/ Campânia e 1 fragmento de uma ânfora ovóide gadi- 
tana, produzida entre os primeiros anos do segundo quartel do século I a.C. até ao início do Século I d.C. $\mathrm{Na}$ pequena lareira enquadrável temporalmente na fase de construção ou utilização do grande edifício identificamos fragmentos de ânforas produzidas na Bética Costeira e no Vale do Guadalquivir, onde está presente a forma Haltern 70 , produzida entre 50 a.C. e o reinado de Augusto e uma Dressel i Bética Costeira Ulterior produzida entre 140/130 a.C. e 30 a 25 a.C. e 1 fragmento de produção Lusitana de tipologia indeterminada.

O espólio datável leva-nos a enquadrar a construção e a utilização deste edifício entre 30 e 15 a.C., intervalo de tempo que abrange a última campanha de pacificação da Hispânia, empreendida por Augusto entre 29 e 19 a.C. contra Cântabros e Astures. $\mathrm{O}$ vasto teatro de operações, para onde foram mobilizadas 6 legiões, abrangeu todo o Noroeste Peninsular, sendo que o Douro, na retaguarda dos avanços e afastado das principais bases do exército romano (González, 1998) terá sido pouco mais do que um ponto de passagem nas rotas que se dirigiam ao Norte, através das quais se abasteciam as legiões que lutavam na frente com o grão proveniente do Sul da Hispânia (Echegaray, 1999). Aventamos a possibilidade do horreum que ora apresentamos se possa ter constituído como um dos entrepostos de apoio à circulação de mantimentos até às frentes de combate, construído nas margens de um rio caudaloso e tantas vezes de difícil travessia nos meses de invernagem, mas ainda assim navegável por 140 quilómetros. O único testemunho da presença de militares no Monte do Castelo de Gaia é atestada pela existência de um cipo funerário identificado a 100 metros do sítio, nas Escadas da Boa Passagem, de L. Lavius Tuscus, natural de Olissipo, militar da $\mathrm{X}$ Gemina, uma das legiões que Augusto deslocou para a Hispânia no decurso da campanha Cantábrica (Cérdan, 2017) e que foi datado de entre Augusto a Tibério por Vasco Mantas (Mantas, 2013).

Os dados recolhidos no decurso da escavação levam-nos a considerar que o embasamento pétreo posto em evidência constituiria a base de um edifício parcialmente construído em madeira ou em argila, materiais que permitiam levantar estruturas de maneira rápida e eficiente ao mesmo tempo que garantiam um bom isolamento dos elementos (Domínguez, 2015), obedecendo assim aos critérios de outras construções erguidas durante campanhas militares. Sendo as construções em argila mais comuns em regiões secas, não é despicienda a ocorrência de construções em terra neste sítio já que pelo menos uma das casas do habitat da Idade do Ferro seria construída com tijolos de adobe, o que demonstra que esta técnica não era estranha à comunidade local.

A homogeneidade do material arqueológico identificado nos depósitos relacionados com o edifício, leva-nos a considerar também que este terá sido utilizado durante poucos anos, não sendo possível distinguir a sua construção da sua utilização, o que poderia significar que foi abandonado após o fim da guerra, depois de deixar de ser útil.

\section{BIBLIOGRAFIA}

CÉRDAN, Angél Morrillo (2017) - El periodo de la "Paz Armada” en el norte de Hispania (19/15 a.C.-15/20 d.C.): ¿la creación de un sistema de defensa sin frontera? In Gérion, Vol. 35, pp. 191-223

DOMÍNGUEZ, Javier S. (2003-2004) - La Documentación Literaria Aplicada al Registro Arqueológico: Las Técnicas de Construcción de lo Graneros Romanos Rurales, in Espacio, Tiempo y Forma, Serie I, Prehistoria y Arqueologia, 16-17.

DOMÍNGUEZ, Javier S. (2008) - La investigación sobre los horrea de época romana: Balance historiográfico y perspectivas de futuro in CuPAUAM, 34, pp. 105-124.

DOMÍNGUEZ, Javier S. (2009) - Los Graneros Romanos Militares de Hispania, in Gladius, Anejos 13. Madrid, Ediciones Polifemo, pp. 679-692.

DOMÍNGUEZ, Javier S. (2015) - Los Granero Sobreelevados en la Hispania Romana: Materiales y Técnicas Contructivas, in Arqueología de la Arquitectura, 12. Madrid/Vitória.

ECHEGARAY, Joaquín G. (1999) - Las Guerras Cântabras en las Fuentes in Guerras Cântabras. Santander. Real Academia de La Historia - Fundacíon Marcelino Botín.

GONZÁLEZ, Julio R. (1998) - As Legiões Romanas no Vale do Douro na Época de Augusto e da Dinastia Júlio-Cláudia (31 A.C. -68 D.C.), in Douro, Estudos e Documentos, Volume III (5), pp. 29-48.

MANTAS, Vasco G. (2013) - População e Mobilidade na Cidades Romanas de Portugal, in I Congresso Histórico Internacional. As Cidades na História - População. Vol. 2. Guimarães, pp. 99-125.

RAMOS, Rui, CARVALHO, José (2020) - Contributo para o Conhecimento das Ocupações Antigas no Monte do Castelo (Vila Nova de Gaia), in Apontamentos de Arqueologia e Património, N.14, Era Arqueolgia.

SILVA, António. M. S. P. (2020) - O Castelo de Gaia, Um Sítio Arqueológico Excepcional e um Valor Cultural a Po- 
tenciar in Actas do IV Congresso de História da Santa Casa da Misericórdia do Porto, Porto, pp. 529-547.

SILVA, António. M. S. P. (2018) - Cale Callaeocorum Locus? Notas Arqueológicas Sobre a Ocupação Indígena e Romana

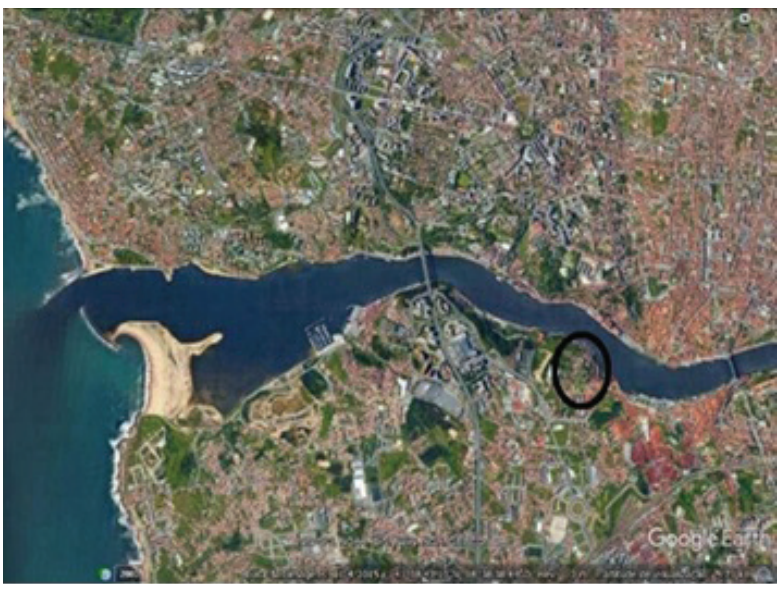

Figura 1

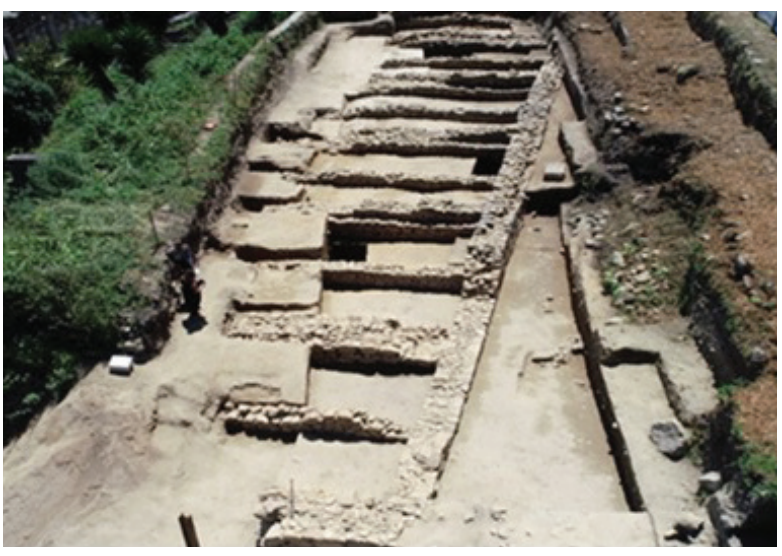

Figura 3

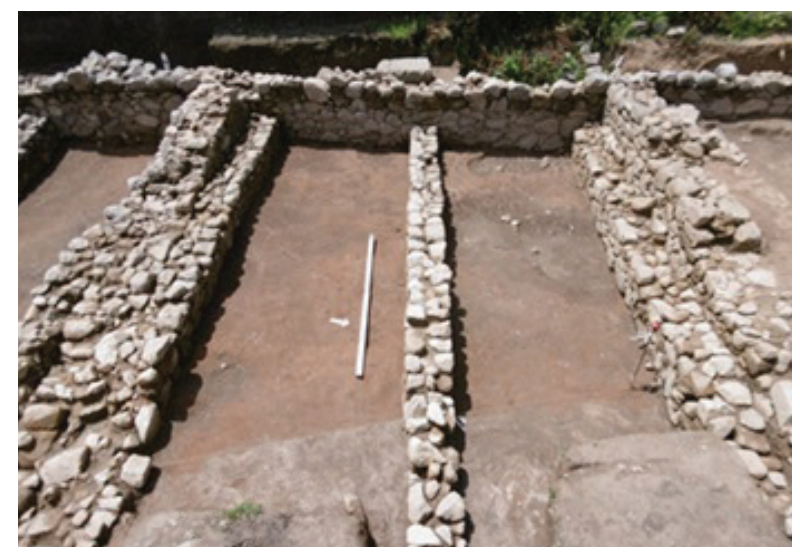

Figura 5 da Foz do Douro, in Actas do Congresso Construir, Navegar, Re(usar) o Douro da Antiguidade, Porto, CICTEM, pp. 45-67.

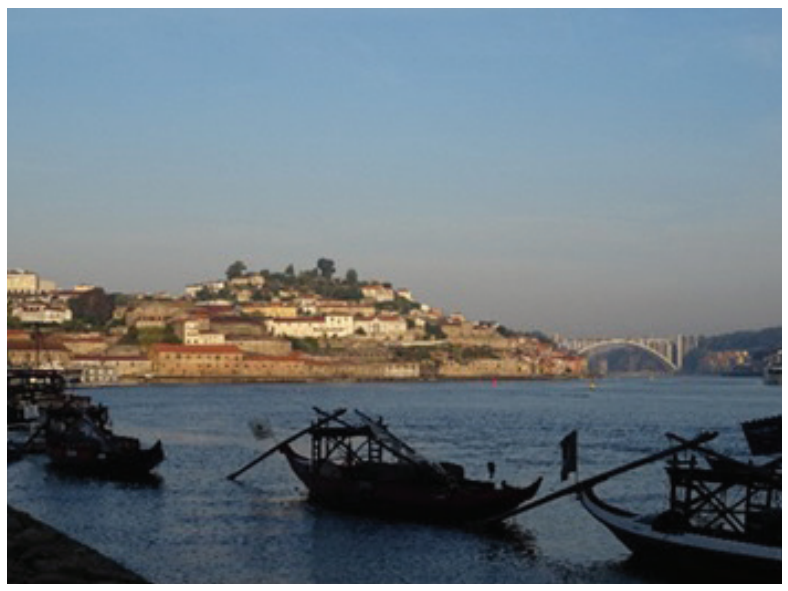

Figura 2

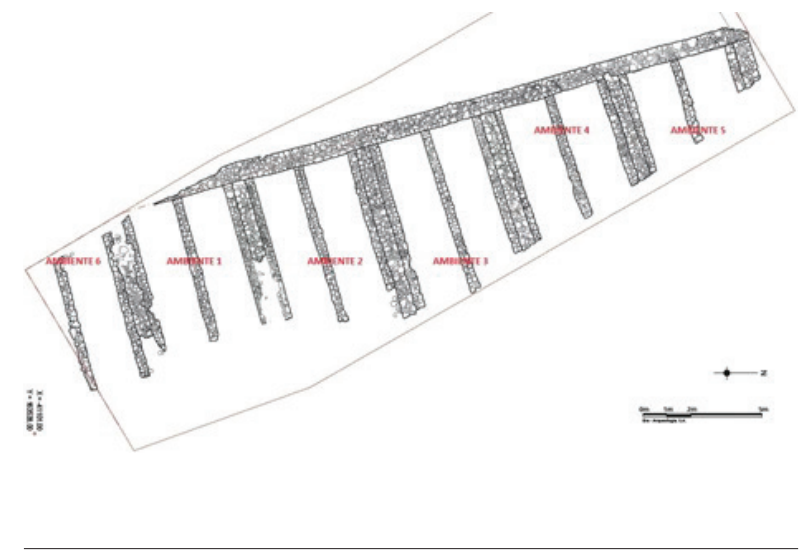

Figura 4 


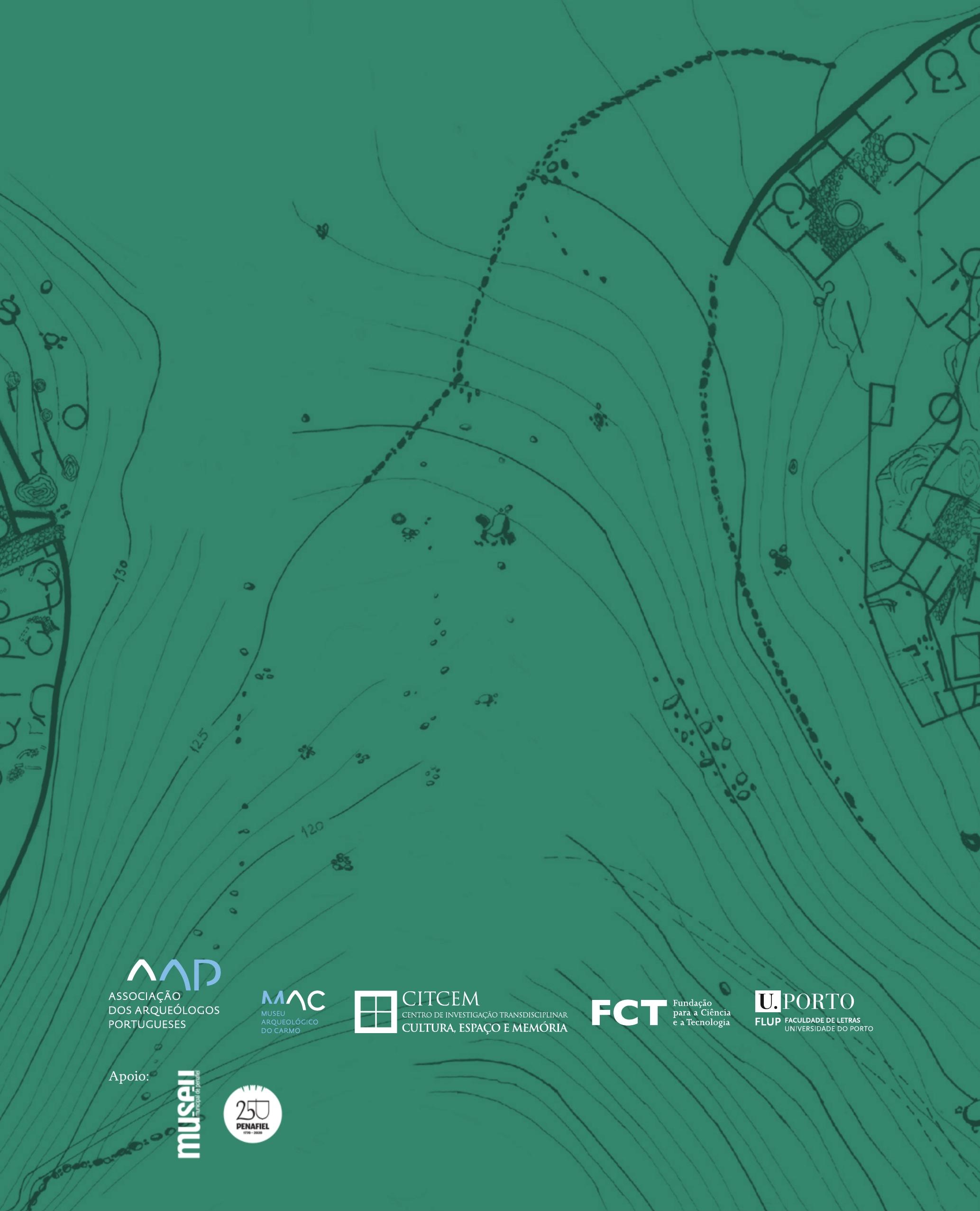

